\title{
Importance of tumor size at diagnosis as a prognostic factor for hepatocellular carcinoma survival: a population-based study
}

This article was published in the following Dove Press journal:

Cancer Management and Research

\section{Guoyi Wu ${ }^{1,2}$ \\ Jing $\mathrm{Wu}^{3}$ \\ Baohua Wang ${ }^{3}$ \\ Xiaolei Zhu ${ }^{4}$ \\ Xiaolei Shi ${ }^{1,2}$ \\ Yitao Ding ${ }^{1,2}$}

'Department of Hepatobiliary Surgery, The Affiliated Drum Tower Hospital of Nanjing University Medical School, Nanjing, China; ${ }^{2}$ Clinical Medical Center for Digestive Disease of Jiangsu Province, Nanjing, China; ${ }^{3}$ National Center for Chronic and Noncommunicable Disease Control and Prevention, Chinese Center for Disease Control and Prevention, Beijing, China; ${ }^{4}$ Office of Noncommunicable Disease Control and Community Health, Chinese Center for Disease Control and Prevention, Beijing, China
Correspondence: Yitao Ding; Xiaolei Shi Department of Hepatobiliary Surgery, The Affiliated Drum Tower Hospital of Nanjing University Medical School, 32I Zhongshan Road, Nanjing, Jiangsu 210008, China

Tel +862568182806

Fax +86 2568182805

EmailmI8936I5I218@I63.com; njsx12000@।63.com
Objective: The effects of hepatocellular carcinoma (HCC) tumor size on clinical presentation and treatment selection and its role as a prognostic factor remain unclear. The present study is a comprehensive analysis of the clinical correlation between tumor size at diagnosis and pathological grades, clinical staging, disparities of treatment, and survival of patients with HCC. Materials and methods: Patients with HCC were separated into groups according to tumor size as follows: $0.1-2.0,2.1-5.0,5.1-10.0$, and $10.1-20.0 \mathrm{~cm}$. Logistic regression analysis was used to determine the relationship between tumor size at diagnosis and pathological grade, Surveillance, Epidemiology, and End Results (SEER) historic stage A, and treatment selection. The survival of HCC patients stratified by tumor size was estimated by Kaplan-Meier and 5-year survival analyses using the log-rank test. Multivariable analysis of overall survival was performed using the Cox proportional hazards model. Tumor size at diagnosis was an independent risk factor of pathological grade, and SEER historic stage A was revealed by logistic regression analysis. Results: The 5 -year survival rate was $21.9 \%$ vs $14.3 \%$ vs $9.2 \%$ vs $7.7 \%$ for all HCC patients and $31.2 \%$ vs $23.6 \%$ vs $20.3 \%$ vs $15.5 \%$ for patients who underwent surgery with tumor sizes of $0.1-2.0$ vs $2.1-5.0$ and 5.1-10.0 vs $10.1-20.0 \mathrm{~cm}$, respectively; multivariable Cox regression analysis identified tumor size at diagnosis as an independent predictor of survival risk with HR of 1.00 vs 1.66 vs 2.92 vs 3.67 , respectively.

Conclusion: Tumor size at diagnosis could be used as an independent risk predictor associated with histological grade, stage, selection of surgery, and survival in HCC.

Keywords: HCC, tumor size, SEER, prognosis, overall survival

\section{Introduction}

Hepatocellular carcinoma (HCC) is the one of the most common lethal cancers and the second leading cause of cancer mortality worldwide. ${ }^{1} \mathrm{HCC}$ is associated with poor prognosis, and the incidence of $\mathrm{HCC}$ is increasing in many countries. ${ }^{2}$ Therefore, it is very important to identify prognostic factors correlated with clinical outcomes. Several staging systems were proposed in the past years, including the Barcelona Clinic Cancer (BCLC) staging system, ${ }^{3}$ the American Joint Committee on Cancer (AJCC) TNM staging system, ${ }^{4}$ the Japan Integrated Staging Score, ${ }^{5}$ and the Hong Kong Liver Cancer staging system. ${ }^{6}$

The BCLC staging system takes into account several variables including tumor burden, the Child-Pugh score, and the patient performance status. Regarding tumor burden, the major prognostic factors of survival are tumor size, tumor number, and vascular invasion. Since tumor size is a known prognostic factor in $\mathrm{HCC}$, with larger 
tumors predicting a worse prognosis in most cases, it has been included in most surgical staging systems for HCC..$^{7-9}$ However, several studies reported controversial results. ${ }^{10-12}$ Because of the negative results reported in these studies, tumor size was excluded from the staging criteria in the latest 6th and 7th editions of the AJCC TNM staging system for HCC. ${ }^{12}$ These conflicting results from the literature exist because data on the diameter of tumor size as a prognostic factor for $\mathrm{HCC}$ are limited.

We hypothesized that tumor size is useful for predicting the prognosis of HCC patients. To test this hypothesis, we analyzed the correlation between tumor size and pathological grade, tumor progression, and the selection of treatment using the Surveillance, Epidemiology, and End Results (SEER) database. The relationship between tumor size and overall survival (OS) was investigated to prove our hypothesis that clinical tumor size at diagnosis can be used to estimate the OS of patients with HCC. Data from a population-based subset from the USA were used to examine the value of tumor size as a prognostic factor in patients undergoing different treatments for HCC.

\section{Materials and methods}

\section{Data source and study population}

The SEER database for 1973-2014 (April 2017 version) was searched for this study. The SEER program is sponsored by the National Cancer Institute. It collects cancer incidence and survival information from 18 population-based cancer registries; $28 \%$ of the US population (seer.cancer.gov/about/ overview.html) is covered. The demographic data, primary lesion location, tumor morphology, tumor stage at diagnosis, surgical treatment performed, and survival status of all patients diagnosed with specific cancers were methodically compiled by each registry. Hispanics, Native Americans, and Asians/Pacific Islanders were oversampled in the SEER program.

ICD for Oncology, 3rd edition (ICD-O-3) site code C22.0 and histologic type ICD-O-3 codes 8170-8175 were used to identify patients diagnosed with HCC between 1988 and 2014 from the SEER database $(90,755 \mathrm{HCC}$ patients). Those HCC patients diagnosed between 1973 and 1987 were excluded (4,878 patients) because of insufficient staging information. Patients diagnosed with unknown age or age $<18$ years (202 patients) and those diagnosed by death certificate or at the time of autopsy (2,088 patients) were excluded. Patients were excluded if their SEER historic stage A was blank(s), in situ, or unstaged (11,426 patients). Cases with unknown race/ethnicity ( 270 patients) and unknown or not stated tumor size $(16,079$ patients) were also excluded. Finally, a total of 57,920 HCC patients matching the specified eligibility criteria were included in the analysis. Detailed exclusion criteria are shown in Figure 1.

From an initial 57,920 HCC patients who met the selection criteria, 17,964 HCC patients with histological grade records met the eligibility criteria for further evaluation of the association between tumor size and pathological grade, and all initial samples had SEER stage A data. HCC patients with or without Surg Prim Site data were available for 16,208 and 41,656 patients, respectively (Figure 1). Patients with incomplete follow-up were removed from the analysis of OS.

\section{Ethics statement}

An independent ethics committee/institutional review board at the Affiliated Drum Tower Hospital of Nanjing University Medical School (China) approved the study. The study was performed in agreement with the Declaration of Helsinki. Informed patient consent is not needed when using data retrieved from the SEER database because de-identified data were used. The access permission to use the research data file in the SEER program was approved by the National Cancer Institute, USA (reference number 12444-Nov2016).

\section{Definitions}

Tumor size was defined as the maximum diameter of the cancer mass based on the priority in order of pathology results, operative observes, or medical imaging reports. Patients without defined tumor size or tumor size $>20 \mathrm{~cm}$ were excluded. Patients with $\mathrm{HCC}$ for further assessment were separated into groups according to tumor size as follows: $0.1-2.0,2.1-5.0$, $5.1-10.0$, and $10.1-20.0 \mathrm{~cm}$.

To ensure a consistent staging classification system for HCC throughout the study period, we used the SEER historical stage A system for the classification. The SEER historical stage A system provides a compatible definition through the period. The more frequently used AJCC staging system was not feasible for the analysis of the datasets before it was adopted by the SEER database. The SEER historical stage A system sorts tumors into localized (tumor was limited to the organ), regional (tumor invaded adjacent tissues or had lymph node metastases), or distant (distant metastasis was observed).

Based on SEER site-specific surgery definitions, we focused on the type of surgical treatment. The different surgical treatments were grouped into the following categories: no surgery performed, tumor-directed treatment, hepatic resection or lobectomy performed, and hepatectomy or transplant 


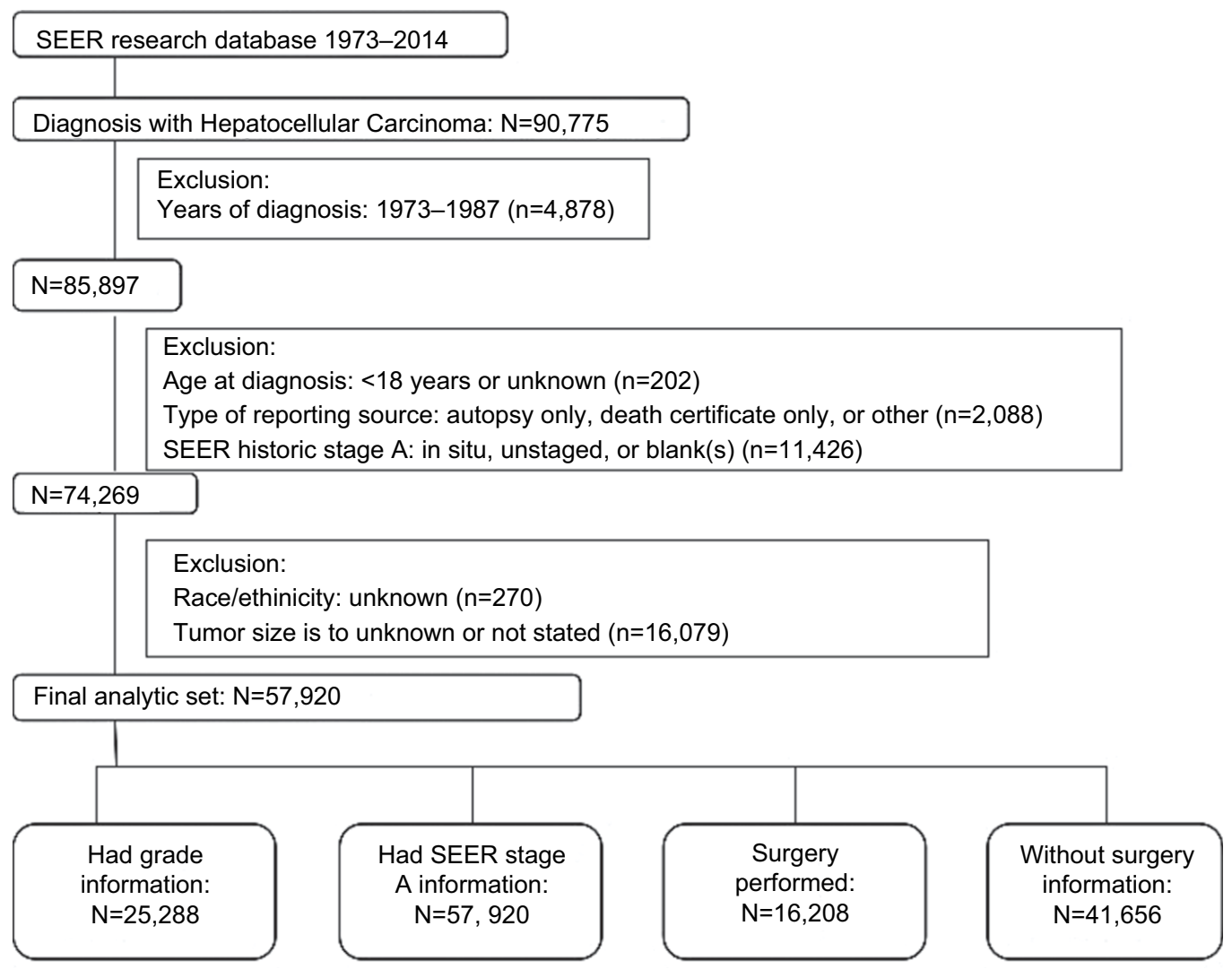

Figure I The patient selection algorithm is shown. Note that some patients met more than one exclusion criteria. Abbreviation: SEER, Surveillance, Epidemiology, and End Results.

performed. Radiofrequency ablation, electrocauterization, photodynamic therapy, electrofulguration, cryotherapy, laser surgery, or alcohol and acetic acid ablation were included in tumor-directed treatment.

\section{Statistical analysis}

Descriptive statistics were calculated for all demographic variables included in the analysis and rendered as proportion (\%) and frequency (n) for each categorical variable. For continuous variables, mean and SD were used. Patient race was classified into White, Black, Asian (Asian/ Pacific Islander), and Native American (American Indian/Alaska native) groups based on the SEER coding manual. Other factors of interest were age, sex, and years since diagnosis. The selection of variables was determined by our medical knowledge and reading previous literatures. The associations of tumor size with pathological grade, SEER historic stage $\mathrm{A}$, and selection of surgery were evaluated by using logistic regression analysis. Categorical variables were compared between different tumor size subgroups using Pearson's chisquared test. Patients diagnosed with HCC between 1988 and 2014 were retrieved for the measurement of OS rates and HRs. Five-year survival was calculated for OS and stratified by tumor size. Kaplan-Meier estimates of survival were stratified by tumor size, and treatment was analyzed using the log-rank test. Multivariable analysis of OS was performed using the Cox proportional hazards model. Results were identified as statistically significant at $P \leq 0.05$, corresponding to $95 \% \mathrm{CI}$. All statistical analyses were performed using SPSS software, version 22 (SPSS Inc., IBM Corporation, Chicago, IL, USA).

\section{Results \\ Patient characteristics}

Based on the patient exclusion criteria described above, 57,920 patients with HCC were retrieved from the SEER database and analyzed. The characteristics of the final study population are presented in Table 1 . The mean age $( \pm \mathrm{SD})$ was $63.47 \pm 11.60$ years, and $76 \%$ were men and $24 \%$ were women. The majority of HCC cases were in the age group of 55-64 years (34\%). Most patients were White (67\%), and the next largest group was Asian/Pacific Islanders (19\%), followed by Black (13\%). Median tumor diameter was 5.97 $\mathrm{cm}$ (range $0.1-20.0)$. Only $1 \%$ of the tumors had a diameter larger than $20 \mathrm{~cm}$. Histological confirmation of the tumor was not available in 34,985 patients in the study group, and most HCC tumors (57\%) were localized. After 1998, detailed treatment information was available for HCC patients. Most 
Table I Characteristics of the study population with HCC between 1988 and $2014(\mathrm{~N}=57,920)$

\begin{tabular}{|c|c|}
\hline Variable & No. of patients (\%) \\
\hline Mean \pm SD age, years & $63.47 \pm 11.60$ \\
\hline \multicolumn{2}{|l|}{ Age (years) } \\
\hline $18-44$ & $2,170(4)$ \\
\hline $45-54$ & $10,410(18)$ \\
\hline $55-64$ & 19,925 (34) \\
\hline $65-74$ & $14,377(25)$ \\
\hline$\geq 75$ & $11,038(19)$ \\
\hline \multicolumn{2}{|l|}{ Sex } \\
\hline Female & $14,107(24)$ \\
\hline Male & $43,813(76)$ \\
\hline \multicolumn{2}{|l|}{ Race/ethnicity } \\
\hline White & $38,749(67)$ \\
\hline Asia/Pacific Islander & $11,213(19)$ \\
\hline Black & $7,256(13)$ \\
\hline Other & $702(1)$ \\
\hline \multicolumn{2}{|l|}{ Tumor size (cm) } \\
\hline $0.1-2.0$ & $7,06 \mid(\mid 2)$ \\
\hline $2.1-5.0$ & $23,7 \mid 4(4 I)$ \\
\hline $5.1-10.0$ & $\mid 8,067(3 \mid)$ \\
\hline $10.1-20.0$ & $8,348(14)$ \\
\hline 0 or $\geq 20.1$ & $730(1)$ \\
\hline \multicolumn{2}{|l|}{ Histological grade } \\
\hline Well differentiated & $7,882(15)$ \\
\hline Moderately differentiated & $9,852(19)$ \\
\hline Poorly differentiated & $4,735(9)$ \\
\hline Undifferentiated & $465(1)$ \\
\hline Unknown & $34,985(67)$ \\
\hline \multicolumn{2}{|l|}{ SEER historic stage A } \\
\hline Localized & $32,818(57)$ \\
\hline Regional & $17,447(30)$ \\
\hline Distant & $7,655(13)$ \\
\hline \multicolumn{2}{|l|}{ Surgical intervention } \\
\hline No surgery or blank & $4 I, 7 I I(7 I)$ \\
\hline Ablation/destruction & $6,189(\mathrm{II})$ \\
\hline Resection & $5,805(10)$ \\
\hline Transplantation & $3,922(7)$ \\
\hline Other & $293(I)$ \\
\hline \multicolumn{2}{|l|}{ Time period } \\
\hline $1988-2003$ & $12,188(2 \mid)$ \\
\hline 2004-2009 & $20,300(35)$ \\
\hline $2010-2014$ & $25,432(44)$ \\
\hline
\end{tabular}

Abbreviations: HCC, hepatocellular carcinoma; SEER, Surveillance, Epidemiology, and End Results.

patients $(71 \%)$ did not undergo any surgical intervention or the surgical information was not available. Of the patients with treatment information, $11 \%$ were treated by local tumor destruction including photodynamic therapy, cryosurgery, percutaneous ethanol injection, or heat-radiofrequency ablation, $10 \%$ underwent liver resection or lobectomy, and $\sim 7 \%$ underwent hepatectomy and transplantation.

\section{Association between tumor size and grade}

Table S1 lists the study patients according to clinical tumor size at diagnosis. From an initial sample of 25,288 HCC patients that met the selection criteria, 22,622 patients with available histological grade records and tumor size $0.1-2 \mathrm{~cm}$ fulfilled the eligibility criteria for evaluating the association of tumor size with pathological grade. Patients with well and moderately differentiated $\mathrm{HCC}$ had significantly smaller tumors $(5.87 \pm 3.96 \mathrm{~cm})$ than those with poorly differentiated/ undifferentiated HCC $(7.27 \pm 4.32 \mathrm{~cm})$. Figure $2 \mathrm{~A}$ shows the distribution of HCC grades according to tumor size. Patients with larger tumors were more likely to have poorly differentiated tumors. The frequency of undifferentiated tumors was significantly higher in the large size tumor groups than in the small size tumor groups ( $13 \%$ vs $18 \%$ vs $26 \%$ vs $32 \%$ in the $0.1-2.0$ vs $2.1-5.0$ vs $5.1-10.0$ vs $10.1-20 \mathrm{~cm}$ groups, respectively, all $P<0.001$ ) (Table $\mathrm{S} 1$ ). Moreover, $60.79 \%$ of tumors in the poorly differentiated and undifferentiated group were large size tumors $(>5 \mathrm{~cm}$ ), whereas $45.08 \%$ of tumors in the well/moderately differentiated group were classified as large size tumors $(>5 \mathrm{~cm})(P<0.001)$. Tumor size was an independent predictor of $\mathrm{HCC}$ pathological grade $(\mathrm{OR}, 1.894$; 95\% CI, 1.777-2.018; $P<0.001)$ was revealed by logistic regression analysis.

\section{Association between tumor size and stage (HCC progression)}

A total of 57,190 patients met the eligibility criteria for evaluating the association of tumor size with SEER historic stage A. The median tumor size of HCC patients with SEER historic stage A was $5.97 \mathrm{~cm}$ (range, 0.1-20). Figure 2B shows the distribution of SEER historic stage A of HCCs according to tumor size. Patients with localized HCC had significantly smaller tumors $(4.92 \mathrm{~cm})$ than those with $\mathrm{HCC}$ with regional metastasis $(6.95 \mathrm{~cm})$. HCC patients with distant metastases had the largest tumor size at $8.33 \mathrm{~cm}$. Increased regional and distant metastasis tumors were observed in the larger size groups. The frequency of regional/distant metastasis tumors was significantly higher in the large size tumor groups than in the small size tumor groups $(22 \% \mathrm{vs}$ $32 \%$ vs $53 \%$ vs $67 \%$ in the $0.1-2.0$ vs $2.1-5.0$ vs $5.1-10.0$ vs $10.1-20 \mathrm{~cm}$ groups, respectively, all $P<0.001$ ) (Table $\mathrm{S} 2)$. Tumor size was an independent predictor of HCC stage (OR, 3.199; 95\% CI, 3.091-3.312; $P<0.001)$ was revealed by logistic regression analysis. 
A

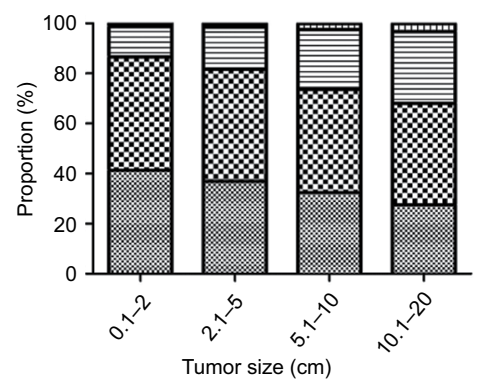

C

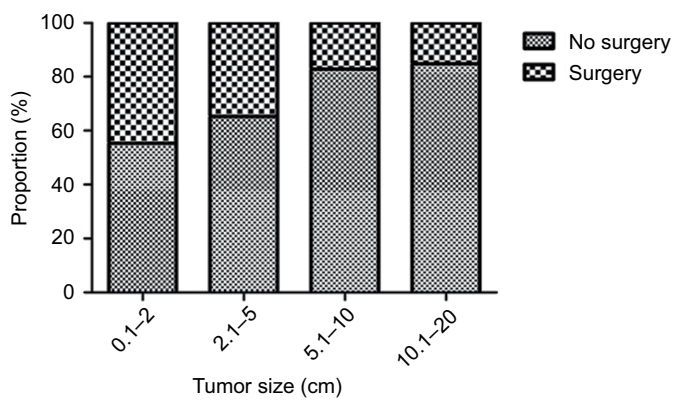

B

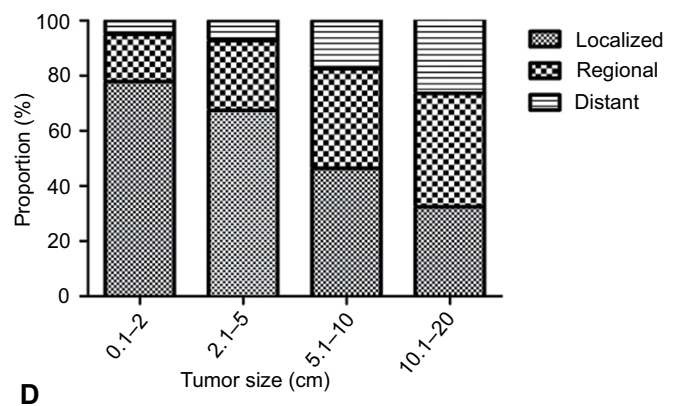

D

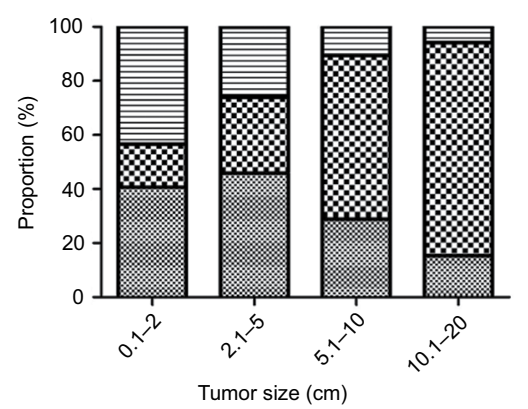

Distruction

$\infty$ Resection

曰 Transplant

Figure 2 (A) Changes in the proportion of HCC histological grade by tumor size. (B) Changes in the proportion of SEER historic stage A by tumor size. (C) Changes in the proportion of surgery by tumor size. (D) Changes in the proportion of different surgery types by tumor size.

Abbreviations: HCC, hepatocellular carcinoma; SEER, Surveillance, Epidemiology, and End Results.

\section{Association between tumor size and treatment selection}

Less than $30 \%$ of all patients received any type of treatment for $\mathrm{HCC}(\mathrm{n}=16,208,27.9 \%)$, and smaller tumor size patients were more likely to receive treatment for HCC than larger size tumor groups $(44.6 \%$ vs $34.7 \%$ vs $17.2 \%$ vs $15.2 \%$ in the $0.1-2.0$ vs $2.1-5.0$ vs $5.1-10.0$ vs $10.1-20.0 \mathrm{~cm}$ groups, respectively, all $P<0.001$ ) (Figure $2 \mathrm{C}$ ). In addition, there were differences in the type of treatment according to tumor size among patient groups that received any form of treatment for HCC (Figure 2D). For example, smaller tumor size group patients were proportionally more likely to be treated surgically with liver transplantation than larger tumor size groups ( $43.3 \%$ vs $25.9 \%$ vs $10.4 \%$ vs $5.8 \%$ in the $0.1-2.0$ vs $2.1-5.0$ vs $5.1-10.0$ vs $10.1-20.0 \mathrm{~cm}$ groups, all $P<0.001$ ), whereas larger tumor size group patients were more likely to receive resection surgery $(16.0 \%$ vs $28.2 \%$ vs $60.8 \%$ vs $78.8 \%$, respectively, all $P<0.001$ ). Logistic regression analysis showed that patients with smaller tumors $(\leq 5 \mathrm{~cm})$ were more likely to undergo cancer-directed surgery (OR, 1.52; 95\% CI, 1.48-1.57; $P<0.001)$. Regarding treatment strategy, patients with smaller size HCCs were strongly advised to undergo tumor destruction or liver transplantation strategies, whereas those with larger tumors $(>5 \mathrm{~cm})$ more often underwent resection.

\section{Survival analysis according to tumor size and stage}

To determine the value of primary tumor size as a prognostic factor in patients with HCC, we further investigated the association between OS and tumor size in the final study population. The 5 -year OS rate of the entire group was $9.5 \%$. For small size tumors $(0.1-2 \mathrm{~cm})$, the 5-year survival rate was $19.2 \%$ (Table 2). Survival decreased with increasing tumor size. Among 32,406 patients with localized HCC only, the 5-year OS rate was $13.7 \%$; it was $21.9 \%$ for patients with tumors $\leq 2 \mathrm{~cm}$ in diameter, decreasing to $14.3 \%$ vs $9.2 \%$ vs $7.7 \%$ for patients with tumor sizes $2.1-5.0$ vs $5.1-10.0$ vs $10.1-20.0 \mathrm{~cm}$, respectively. OS rate was similar across tumor size categories in patients with regional invasion. The relationship between HCC tumor size and OS stratified by SEER historic stage A is shown in Figure 3A.

\section{Survival in patients who underwent surgery}

A total of 16,581 patients received surgical resection treatment. The 5-year OS rate was $23.8 \%$ after surgery compared with $4.0 \%$ in patients who did not receive surgery (Table S3). When surgery was performed, patients with tumors $<2 \mathrm{~cm}$ had better 5-year OS rates than other groups with larger tumor size: the 5 -year survival rate was $31.2 \%$ in patients 
Table 2 Tumor size and survival according to SEER stage $A$

\begin{tabular}{|l|l|l|l|}
\hline $\begin{array}{l}\text { Tumor } \\
\text { size }(\mathbf{c m})\end{array}$ & No. of patients & \multicolumn{2}{|c|}{ Survival rate (\%)* } \\
\cline { 3 - 4 } & (\%) & 3 Years & 5 Years \\
\hline All stages & $56,904(100)$ & 18.0 & 9.5 \\
$0.1-2$ & $7,009(12)$ & 33.7 & 19.2 \\
$2.1-5$ & $23,604(4 I)$ & 22.5 & 11.7 \\
$5.1-10$ & $17,978(32)$ & 10.9 & 5.5 \\
I0.I-20 & $8,313(15)$ & 7.4 & 3.8 \\
Localized & $32,406(100)$ & 25.4 & 13.7 \\
$0.1-2$ & $5,456(17)$ & 37.6 & 21.9 \\
$2.1-5$ & $15,915(49)$ & 27.3 & 14.3 \\
$5.1-10$ & $8,345(26)$ & 17.4 & 9.2 \\
I0.I-20 & $2,690(8)$ & 14.4 & 7.7 \\
Regional & $17,117(100)$ & 10.6 & 5.1 \\
$0.1-2$ & $1,205(7)$ & 24.1 & 11.9 \\
$2.1-5$ & $5,978(35)$ & 15.1 & 7.6 \\
$5.1-10$ & $6,499(38)$ & 6.7 & 3.0 \\
I0.I-20 & $3,435(20)$ & 5.3 & 2.4 \\
Distant & $7,382(100)$ & 2.8 & 1.1 \\
$0.1-2$ & $349(5)$ & 6.3 & 2.6 \\
$2.1-5$ & $1,711(23)$ & 3.7 & 1.3 \\
$5.1-10$ & $3,134(43)$ & 2.4 & 0.8 \\
I0.I-20 & $2,188(29)$ & 2.1 & 1.1 \\
\hline
\end{tabular}

Notes: Values in parentheses are percentages. ${ }^{*}$ Calculated by Kaplan-Meier analysis.

Abbreviation: SEER, Surveillance, Epidemiology, and End Results.

with smaller size tumors after surgery, decreasing to $23.6 \%$ vs $20.3 \%$ vs $15.5 \%$ in patients with tumor sizes $2.1-5.0$ vs $5.1-10.0$ vs $10.1-20.0 \mathrm{~cm}$, respectively. The relationship between tumor size and survival in the different treatment groups is shown in Figure 3B.

\section{Predictors of HCC survival}

On multivariate regression analysis, age, sex, tumor size, grade, stage, surgical intervention, and year of diagnosis were associated with OS. Compared with the small tumor size cohort, larger tumor size patients had significantly worse OS, with $\mathrm{HR}$ values of 1.00 vs 1.66 vs 2.92 vs 3.67 for the $0.1-2.0$ vs $2.1-5.0$ vs $5.1-10.0$ vs $10.1-20.0 \mathrm{~cm}$ groups, respectively (Table 3). Advanced histological grade (HR, 2.16, $P<0.001$ ), distant metastases stage (HR, 3.99, $P<0.001$ ), and no surgery performed $(\mathrm{HR}, 3.79, P<0.001)$ were significant independent predictors of poor OS.

\section{Discussion}

In the present study, analysis of population-based cancer registry data from the United States identified tumor size as an independent risk factor for the survival of patients with $\mathrm{HCC}$ and was associated with $\mathrm{HCC}$ differentiation, stage, and selection of treatment. Larger tumor size was associated with less differentiated tumors, more advanced stage, and lower survival compared with smaller tumor size groups. This finding may influence staging and treatment decisions in HCC.

As an important prognostic factor in HCC, tumor size is included in several staging systems such as the 6th and 7th editions of the AJCC TNM staging system, ${ }^{12,13}$ Japan TNM staging system by the liver cancer study group, ${ }^{8}$ and Hong Kong HCC staging system. ${ }^{5}$ However, the negative correlation between tumor size and other critical adverse prognostic factors such as vascular invasion, poorly differentiated tumors, and multiple lesions was reported in some large cohort studies. ${ }^{11,14}$ Thus, the significance of tumor size at diagnosis as a prognostic factor for HCC remains controversial ..$^{15,16}$

Hence, tumor size at diagnosis as a prognostic factor for HCC was excluded in the 6th and 7th editions of the AJCC TNM classification system. ${ }^{17,18}$ Several studies later downplayed the importance of tumor size at diagnosis by demonstrating its lack of significance as a prognostic factor for HCC. ${ }^{19,20}$ However, in the latest 8 th edition of the AJCC TNM classification system, $\mathrm{T} 1$ is subdivided into $\mathrm{T} 1 \mathrm{a}$ and $\mathrm{T} 1 \mathrm{~b}$ based on a cutoff size of $2 \mathrm{~cm} .{ }^{21}$ The importance of tumor cutoff sizes of 5 and $10 \mathrm{~cm}$ as independent prognostic factors of HCC remains controversial, and further clinical studies are needed to clarify the relationship between tumor size and outcome in HCC. The present study indicated that with a tumor cutoff size of 5 or $10 \mathrm{~cm}$, OS differs significantly among groups regardless of stage or the type of surgery. These findings also suggest that tumor size has a significant effect on the 5-year survival rate after surgery in HCC.

The results of the present study indicate that even after surgery, tumor size is an independent risk factor for HCC survival. The 5-year survival rate was significantly higher in patients who underwent surgery than in those who did not undergo surgery $(23.8 \%$ vs $4.0 \%)$. Therefore, tumor size may be an important factor for the prognosis of HCC patients after surgery, which is consistent with the results of previous studies.

HCC tumor size is associated with genetic changes and pathological features. ${ }^{22,23}$ For example, larger tumor size is associated with capsular invasion, tumor thrombi, satellite nodules, and noninvasive growth patterns. Moreover, larger HCC tumor size stimulates invasive behavior. ${ }^{24}$ Thus, recurrence and metastasis may be more commonly observed in patients with large size HCC than in those with small size HCC. The patients with larger tumors associated with unfavorable HCC phenotypes may clarify why large size HCC did not confer a survival benefit after treatment compared with that in patients with small size HCC. 

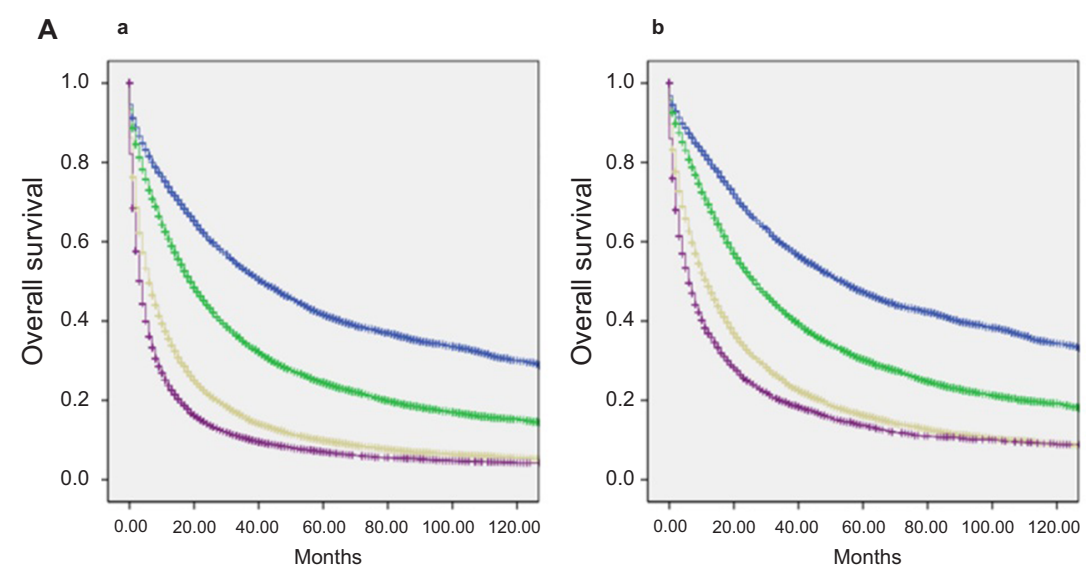

Tumor size (cm)

$+0.1-2.0$

$+2.1-5.0$

+5.1-10.0

+ 10.1-20.0
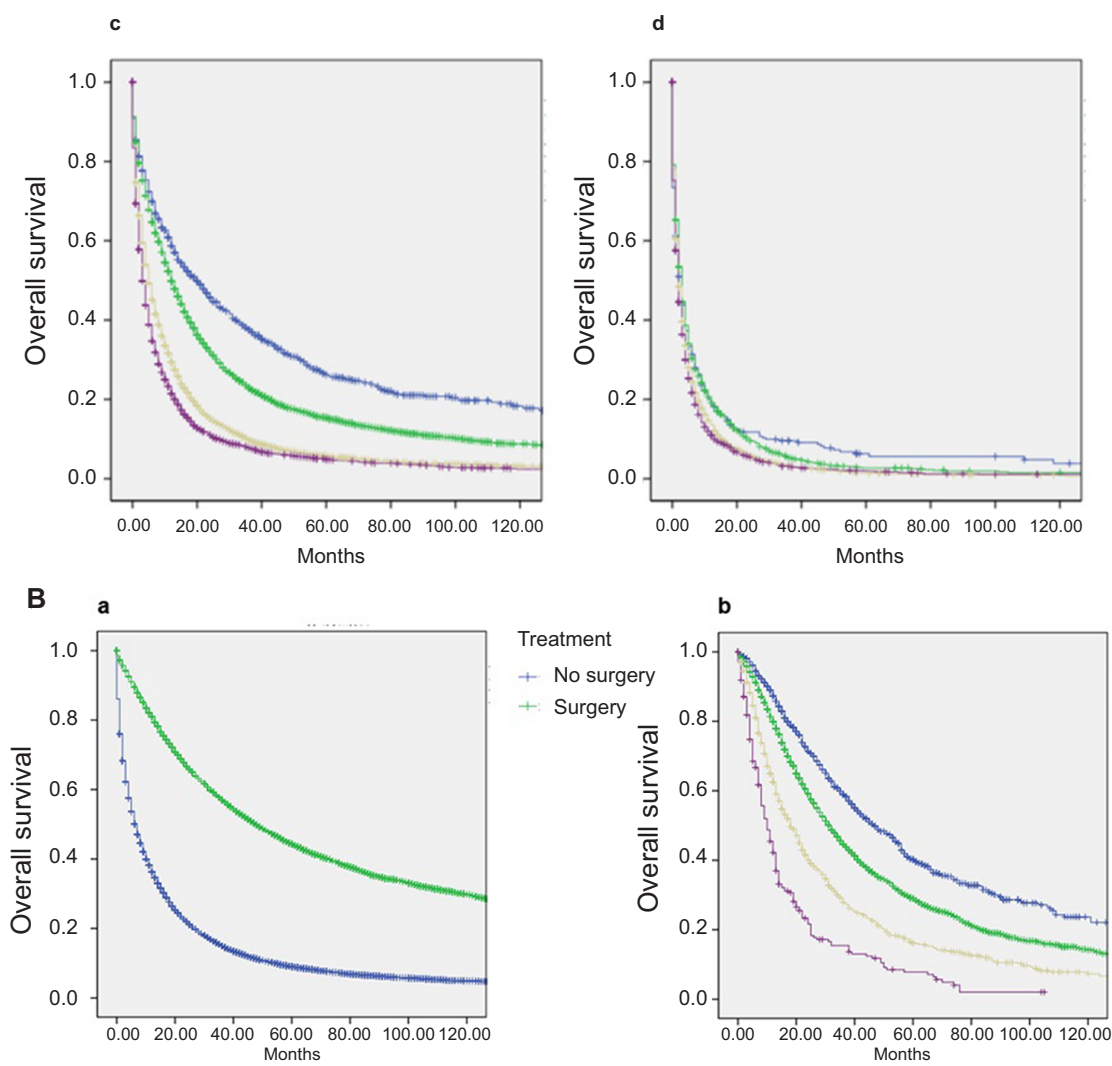

Tumor size $(\mathrm{cm})$

$+0.1-2.0$

$+2.1-5.0$

5.1-10.0

$+10.1-20.0$
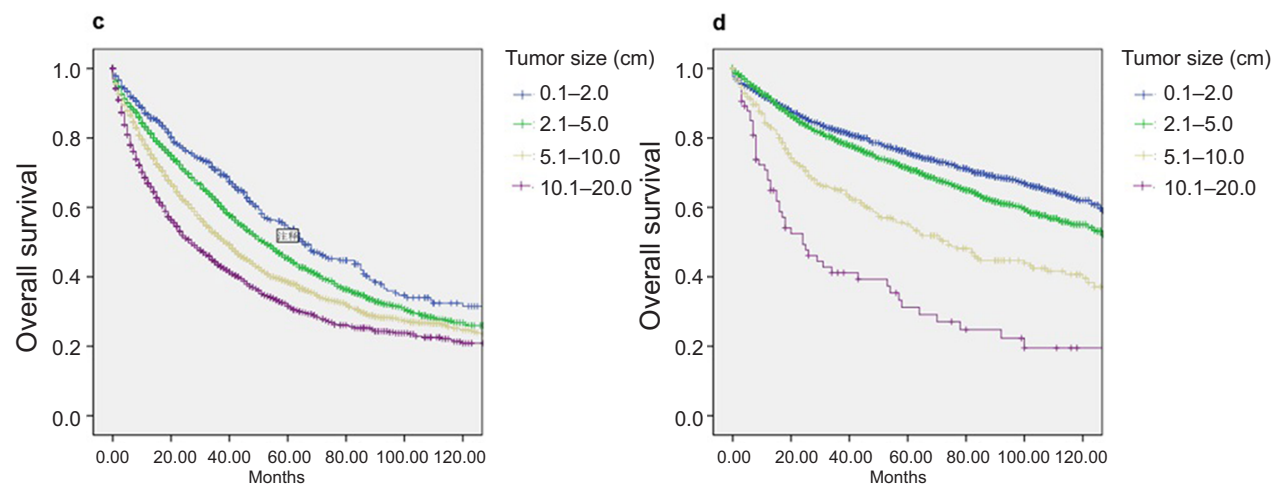

Figure 3 (A) Survival by tumor size $(\mathrm{cm})$ and stage of HCC was determined using Kaplan-Meier curves: a, all stages; b, localized; c, regional; and d, distant. (B) Survival by tumor size $(\mathrm{cm})$ and different surgical types was determined using Kaplan-Meier curves: a, surgery vs no surgery; b, destruction; c, resection; and d, transplant.

Abbreviation: HCC, hepatocellular carcinoma. 
Table 3 Cox proportional multivariate analysis of factors associated with overall survival in HCC patients

\begin{tabular}{|c|c|c|}
\hline Characteristics & HR (95\% Cl) & $P$-value \\
\hline \multicolumn{3}{|l|}{ Age (years) } \\
\hline $18-44$ & 1.00 (reference) & \\
\hline $45-54$ & $1.08(0.96-1.22)$ & 0.195 \\
\hline $55-64$ & $1.60(1.43-1.80)$ & $<0.001$ \\
\hline $65-74$ & $1.51(1.34-1.70)$ & $<0.001$ \\
\hline$\geq 75$ & $1.48(1.30-1.69)$ & $<0.001$ \\
\hline \multicolumn{3}{|l|}{ Sex } \\
\hline Male & 1.00 (reference) & \\
\hline Female & $0.94(0.90-0.97)$ & $<0.001$ \\
\hline \multicolumn{3}{|l|}{ Tumor size $(\mathrm{cm})$} \\
\hline $0.1-2.0$ & 1.00 (reference) & \\
\hline $2.1-5.0$ & $1.66(1.56-1.77)$ & $<0.001$ \\
\hline $5.1-10.0$ & $2.92(2.74-3.11)$ & $<0.001$ \\
\hline $10.1-20.0$ & $3.67(3.43-3.92)$ & $<0.001$ \\
\hline \multicolumn{3}{|l|}{ Histological grade } \\
\hline Well & 1.00 (reference) & \\
\hline Moderately & $1.59(1.53-1.65)$ & $<0.001$ \\
\hline Poorly & $2.16(2.08-2.24)$ & $<0.001$ \\
\hline \multicolumn{3}{|l|}{ SEER historic stage $A$} \\
\hline Localized & 1.00 (reference) & \\
\hline Regional & $1.96(1.89-2.03)$ & $<0.001$ \\
\hline Distant & $3.99(3.80-4.18)$ & $<0.001$ \\
\hline \multicolumn{3}{|l|}{ Surgical intervention } \\
\hline Surgery & 1.00 (reference) & \\
\hline No surgery & $3.79(3.67-3.93)$ & $<0.001$ \\
\hline \multicolumn{3}{|l|}{ Time period } \\
\hline 1988-2003 & 1.00 (reference) & \\
\hline 2004-2009 & $0.83(0.80-0.86)$ & $<0.001$ \\
\hline $2010-2014$ & $0.77(0.74-0.81)$ & $<0.001$ \\
\hline
\end{tabular}

Abbreviations: HCC, hepatocellular carcinoma; SEER, Surveillance, Epidemiology, and End Results.

The present study had several limitations associated with its retrospective study characteristics and the use of a national cancer registry database. The SEER historical stage A system is different from the commonly used AJCC staging system and may have fewer clinical correlations. However, this classification system allowed the staging of HCC with consistent criteria throughout the study period. The SEER database is limited by its lack of central pathological review. However, previous reports showed good agreement between the cancer histological subtypes reported by the SEER database and histological reports assigned by independent reviewers. The SEER data are also limited in relation to the recording of chemotherapy use. The completeness of the records and the potential biases associated with reasons for the use of chemotherapy were illustrated previously. Records with missing values in this study were excluded; this may be the best approach available at present. Although this method diminishes selection bias and increases universality, the results must be interpreted with caution. Prospectively, risk stratification for predicting metastasis and survival of HCC patients will be improved by adding specific tumor cell phenotypes.

\section{Conclusion}

The results of the present study supported that tumor size at diagnosis is an independent prognostic factor for OS in HCC, regardless of tumor grade, stage, or selection of treatments. These results strongly suggest that the 8 th edition of the AJCC TNM staging system was improved by the separation of early-stage HCC according to tumor size $\leq 2$ or $>2 \mathrm{~cm}$. However, the present findings suggest that the HCC staging systems can be further improved by division into substages based on tumor cutoff sizes of 5 and $/$ or $10 \mathrm{~cm}$.

\section{Acknowledgments}

We thank Dr Shicheng Yu at China CDC for his comments on the statistics. This study was funded by the National Key Research and Development Program of China (grant no. 2016YFC1302603). Guoyi Wu and Jing Wu shared co-first authorship.

\section{Author contributions}

GW, YD, and XS conceived of and designed the study. GW and JW performed the analyses. GW and BW prepared all figures and tables. GW and XZ wrote the main manuscript. All authors contributed toward data analysis, drafting and critically revising the paper and agree to be accountable for all aspects of the work.

\section{Disclosure}

The authors report no conflicts of interest in this work.

\section{References}

1. Ferlay J, Soerjomataram I, Dikshit R, et al. Cancer incidence and mortality worldwide: sources, methods and major patterns in GLOBOCAN 2012. Int J Cancer. 2015;136(5):E359-E386.

2. Siegel RL, Miller KD, Jemal A, Statistics C. CA Cancer J Clin. 2018;2018(68):7-30.

3. Hsu CY, Liu PH, Ho SY, Sy H, et al. Using nomogram of the Barcelona Clinic Liver Cancer system for treatment selection in patients with stage C hepatocellular carcinoma. BMC Cancer. 2018;18(1):289.

4. Kamarajah SK, Frankel TL, Sonnenday C, Cho CS, Nathan H. Critical evaluation of the American Joint Commission on Cancer (AJCC) 8th edition staging system for patients with Hepatocellular Carcinoma (HCC): a Surveillance, Epidemiology, End Results (SEER) analysis. J Surg Oncol. 2018;117:644-650.

5. Yau T, Tang VY, Yao TJ, Fan ST, Lo CM, Poon RT. Development of Hong Kong Liver Cancer staging system with treatment stratification for patients with hepatocellular carcinoma. Gastroenterology. 2014;146(7):1691-1700.

6. Nishikawa H, Kita R, Kimura T, et al. Proposal of the performance status combined Japan Integrated Staging system in hepatocellular carcinoma complicated with cirrhosis. Int J Oncol. 2015;46(6):2371-2379. 
7. Goh BK, Teo JY, Chan CY, et al. Importance of tumor size as a prognostic factor after partial liver resection for solitary hepatocellular carcinoma: implications on the current AJCC staging system. J Surg Oncol. 2016;113(1):89-93.

8. Minagawa M, Ikai I, Matsuyama Y, Yamaoka Y, Makuuchi M. Staging of hepatocellular carcinoma: assessment of the Japanese TNM and AJCC/ UICC TNM systems in a cohort of 13,772 patients in Japan. Ann Surg. 2007;245(6):909-922.

9. Pons F, Varela M, Llovet JM. Staging systems in hepatocellular carcinoma. HPB. 2005;7(1):35-41.

10. Vauthey JN, Lauwers GY, Esnaola NF, et al. Simplified staging for hepatocellular carcinoma. J Clin Oncol. 2002;20(6):1527-1536.

11. Zhang H, Yuan SX, Dai SY, et al. Tumor size does not independently affect long-term survival after curative resection of solitary hepatocellular carcinoma without macroscopic vascular invasion. World J Surg. 2014;38(4):947-957.

12. Edge SB, Byrd DR, Compton CC. AJCC Cancer Staging Manual. 7th ed. New York: NY: Springer; 2010.

13. Vauthey JN, Klimstra D, Blumgart LH. A simplified staging system for hepatocellular carcinomas. Gastroenterology. 1995;108(2):617-618.

14. Varotti G, Ramacciato G, Ercolani G, et al. Comparison between the fifth and sixth editions of the AJCC/UICC TNM staging systems for hepatocellular carcinoma: multicentric study on 393 cirrhotic resected patients. Eur J Surg Oncol. 2005;31(7):760-767.

15. Hwang S, Lee YJ, Kim KH, et al. The impact of tumor size on long-term survival outcomes after resection of solitary hepatocellular carcinoma: single-institution experience with 2558 patients. J Gastrointest Surg. 2015;19(7):1281-1290.

16. Huang WJ, Jeng YM, Lai HS, Sheu FY, Lai PL, Yuan RH. Tumor size is a major determinant of prognosis of resected stage I hepatocellular carcinoma. Langenbecks Arch Surg. 2015;400(6):725-734.
17. Lei HJ, Chau GY, Lui WY, et al. Prognostic value and clinical relevance of the 6th Edition 2002 American Joint Committee on Cancer staging system in patients with resectable hepatocellular carcinoma. J Am Coll Surg. 2006;203(4):426-435.

18. Chun YH, Kim SU, Park JY, et al. Prognostic value of the 7th edition of the AJCC staging system as a clinical staging system in patients with hepatocellular carcinoma. Eur J Cancer. 2011;47(17):2568-2575.

19. Yang LY, Fang F, Ou DP, Wu W, Zeng ZJ, Wu F. Solitary large hepatocellular carcinoma: a specific subtype of hepatocellular carcinoma with good outcome after hepatic resection. Ann Surg. 2009;249(1): $118-123$.

20. Kluger MD, Salceda JA, Laurent A, et al. Liver resection for hepatocellular carcinoma in 313 Western patients: tumor biology and underlying liver rather than tumor size drive prognosis. $J$ Hepatol. 2015;62(5):1131-1140.

21. Chun YS, Pawlik TM, Vauthey JN. 8th edition of the AJCC Cancer Staging Manual: pancreas and hepatobiliary Cancers. Ann Surg Oncol. 2018;25(4):845-847.

22. Wong N, Lai P, Lee SW, et al. Assessment of genetic changes in hepatocellular carcinoma by comparative genomic hybridization analysis: relationship to disease stage, tumor size, and cirrhosis. Am J Pathol. 1999;154(1):37-43.

23. Lu XY, Xi T, Lau WY, et al. Pathobiological features of small hepatocellular carcinoma: correlation between tumor size and biological behavior. J Cancer Res Clin Oncol. 2011;137(4):567-575.

24. Pawlik TM, Delman KA, Vauthey JN, et al. Tumor size predicts vascular invasion and histologic grade: implications for selection of surgical treatment for hepatocellular carcinoma. Liver Transpl. 2005;11(9):1086-1092. 


\section{Supplementary materials}

Table SI Characteristics of HCC histological grade by tumor size

\begin{tabular}{|c|c|c|c|c|c|c|}
\hline \multirow{3}{*}{$\begin{array}{l}\text { Histological } \\
\text { grade }\end{array}$} & \multicolumn{4}{|c|}{ Tumor size $(\mathrm{cm}) \mathrm{n}=22,622$} & \multirow{3}{*}{$\begin{array}{l}\text { Chi- } \\
\text { squared } \\
\text { test }\end{array}$} & \multirow[t]{3}{*}{$P$-value } \\
\hline & \multirow{2}{*}{\begin{tabular}{|l|}
$0.1-2.0$ \\
$(n=2,55 I)$
\end{tabular}} & \multirow{2}{*}{$\begin{array}{l}2.1-5.0 \\
(n=9,078) \\
n(\%)\end{array}$} & \multirow{2}{*}{$\begin{array}{l}5.1-10.0 \\
(n=7,383)\end{array}$} & \multirow{2}{*}{$\begin{array}{l}10.1-20.0 \\
(n=3,6 \mid 0) \\
n(\%)\end{array}$} & & \\
\hline & & & & & & \\
\hline Well & $\mathrm{I}, 056(4 \mathrm{I})$ & $3,347(37)$ & $2,397(32)$ & $995(28)$ & 494.104 & $<0.001$ \\
\hline Moderately & $\mathrm{I}, \mathrm{I} 52(45)$ & $4,078(45)$ & $3,039(4 I)$ & $\mathrm{I}, 464(4 \mathrm{I})$ & & \\
\hline Poorly & $309(12)$ & $\mathrm{I}, 528(\mathrm{I})$ & $\mathrm{I}, 764(24)$ & $\mathrm{I}, 036(29)$ & & \\
\hline Undifferentiated & $34(I)$ & $125(1)$ & $183(2)$ & $115(3)$ & & \\
\hline
\end{tabular}

Abbreviation: $\mathrm{HCC}$, hepatocellular carcinoma.

Table S2 Characteristics of SEER historic stage A by tumor size

\begin{tabular}{|c|c|c|c|c|c|c|}
\hline \multirow{3}{*}{$\begin{array}{l}\text { SEER historic } \\
\text { stage A }\end{array}$} & \multicolumn{4}{|c|}{ Tumor size $(\mathrm{cm})(\mathrm{N}=57,190)$} & \multirow{3}{*}{$\begin{array}{l}\text { Chi- } \\
\text { squared } \\
\text { test }\end{array}$} & \multirow[t]{3}{*}{$P$-value } \\
\hline & \multirow{2}{*}{$\begin{array}{l}0.1-2.0 \\
(n=7,061)\end{array}$} & \multirow{2}{*}{$\begin{array}{l}2.1-5.0 \\
(n=23,7 \mid 4) \\
n(\%)\end{array}$} & \multirow{2}{*}{$\begin{array}{l}5.1-10.0 \\
(n=18,067) \\
n(\%) \\
\end{array}$} & \multirow{2}{*}{$\begin{array}{l}10.1-20.0 \\
(n=8,348) \\
n(\%)\end{array}$} & & \\
\hline & & & & & & \\
\hline Localized & $5,496(78)$ & $|5,99|(67)$ & $8,384(46)$ & $2,70 \mathrm{I}(32)$ & $5,749.760$ & $<0.001$ \\
\hline Regional & $1,212(17)$ & $6,000(25)$ & $6,527(36)$ & 3,447 (4I) & & \\
\hline Distant & $353(5)$ & I,723 (7) & $3,156(17)$ & $2,200(26)$ & & \\
\hline
\end{tabular}

Abbreviation: SEER, Surveillance, Epidemiology, and End Results.

Table S3 Tumor size and survival according to surgery

\begin{tabular}{|c|c|c|c|c|}
\hline & & \multirow{2}{*}{$\begin{array}{l}\text { No. of patients (\%) } \\
3 \text { Years }\end{array}$} & \multicolumn{2}{|c|}{ Survival rate (\%) } \\
\hline & & & 5 Years & \\
\hline \multicolumn{2}{|l|}{ All patients } & $56,904(100)$ & 18.0 & 9.5 \\
\hline \multicolumn{2}{|l|}{ No surgery } & $4 I, 138(72)$ & 9.5 & 4.0 \\
\hline \multicolumn{2}{|l|}{ After surgery } & $15,766(28)$ & 40.3 & 23.8 \\
\hline \multicolumn{2}{|c|}{ After surgery subgroup } & \multicolumn{3}{|l|}{$\mathrm{N}=15,766(100)$} \\
\hline \multirow[t]{4}{*}{ Tumor size $(\mathrm{cm})$} & $0.1-2$ & $3,149(20)$ & 49.6 & 31.2 \\
\hline & $2.1-5$ & $8,239(52)$ & 40.6 & 23.6 \\
\hline & $5.1-10$ & $3,110(20)$ & 34.5 & 20.3 \\
\hline & $10.1-20$ & $1,268(8)$ & 29.1 & 15.5 \\
\hline
\end{tabular}

\section{Publish your work in this journal}

Cancer Management and Research is an international, peer-reviewed open access journal focusing on cancer research and the optimal use of preventative and integrated treatment interventions to achieve improved outcomes, enhanced survival and quality of life for the cancer patient. The manuscript management system is completely online and includes a very quick and fair peer-review system, which is all easy to use. Visit http://www.dovepress.com/testimonials.php to read real quotes from published authors. 